\title{
АКТУАЛЬНЫЕ ПРОБЛЕМЫ ПРОВЕДЕНИЯ АНТИКОРРУПЦИОННОЙ ЭКСПЕРТИЗЫ НОРМАТИВНЫХ ПРАВОВЫХ АКТОВ ОРГАНАМИ ПРОКУРАТУРЫ РФ
}

\begin{abstract}
Аннотация: Статья посвящена дискуссионным вопросам проведения антикоррупционной экспертизы вступивших в силу нормативных правовых актов органами Прокуратуры РФ. Предметом проведенного исследования выступает надзорная экспертиза в срере противодействия коррупции.Автор подробно рассматривает отличительные особенности экспертиз на коррупциогенность, проводимых органами прокуратуры, а также отличия от аналогичной экспертизы, осуществляемой другими субъектами. В публикации ведется дискуссия о роли Следственного комитета Российской Федерации в проведении антикоррупционной экспертизы. Особое внимание уделяется судебному рассмотрению требований прокуратуры. Методологической основой проведенного нами исследования является диалектический материализм и основанные на нем универсальные общенаучные методы познания как то: сравнение, анализ, синтез и другие. Автор делает заключение о том, что надзорная экспертиза, проводимая органами прокуратуры, является одним из наиболее результативных видов экспертизы, в силу отсутствия зависимости от органов разработчиков нормативных правовых актов, с одной стороны, и регулярности проведения антикоррупционной экспертизы и, как следствие, наработанного большого опыта в этой области, с другой стороны.В заключение в статье обосновывается необходимость внесения изменений в в часть 1 статьи 251 Гражданского процессуального кодекса РФ «Подача заявления об оспаривании нормативных правовых актов»

Ключевые слова: антикоррупционная экспертиза, органы прокуратуры, особенности, независимость, коррупция, надзорная экспертиза, нормативные правовые акты, противодействие коррупции, Следственный Комитет $Р \Phi$, Прокуратура РФ.
\end{abstract}

$\mathrm{B}$ связи с небывалыми масштабами роста коррупции в последнее время особую актуальность приобрела антикоррупционная экспертиза нормативных правовых актов, как одна из наиболее удачных мер по профилактике коррупционных практик. Федеральный закон «Об антикоррупционной экспертизе нормативных правовых актов и проектов нормативных правовых актов» ${ }^{1}$ выделяет несколько субъектов, проводящих экспертизу на коррупциогенность. Среди них нельзя не отметить особой роли органов прокуратуры в проведении антикоррупционной экспертизы.

Прокуратура РФ, в отличие от Минюста России, занимается в обязательном порядке антикоррупционной экспертизой действующих нормативных правовых актов, а не их проектов.

Можно выделить следующие отличительные черты антикоррупционной экспертизы, проводимой органами прокуратуры:

Ст.2 Ф3 “Об антикоррупционной экспертизе нормативных правовых актов и проектов нормативных правовых актов” от 17 июля 2009 г. № 172-ФЗ. СЗ РФ. 2009. № 29 ст. 3609.
- проводится в отношении действующих нормативных правовых актов;

- проводится в отношении не любых нормативных правовых актов, а только тех, которые указаны в ч. 2 ст. 3 Закона об антикоррупционной экспертизе (хотя в соответствии с приказом Генеральной прокуратуры от 28.12.2009 г. № 400 «Об организации проведения антикоррупционной экспертизы нормативных правовых актов» органам прокуратуры предписано продолжить практику информирования правотворческих органов о наличии коррупциогенных факторов в нормативных правовых актах, не относящихся к категории актов, установленных ч. 2 ст. 3 Закона об антикоррупционной экспертизе);

- проводится в отношении нормативных правовых актов не выше уровня федеральных министерств, служб и агентств;

- в случае выявления в правовом акте коррупциогенных факторов выносится требование прокурора об изменении нормативного правового акта; 
- требование прокурора об изменении нормативного правового акта может быть обжаловано в установленном порядке.

Существуют явные отличия экспертизы на коррупциогенность, проводимой органами прокуратуры, от аналогичной экспертизы, проводимой другими субъектами (например, федеральными органами исполнительной власти), а именно:

- обязанность разработчика реагировать на требования прокурора. Отказ от рекомендаций, сделанных в результате антикоррупционной экспертизы, проводимой Минюстом России и независимыми экспертами, не влечет для разработчиков никаких юридических последствий;

- независимость органов прокуратуры. Ведомственная антикоррупционная экспертиза не исключает субъективного подхода в процессе нормотворческой деятельности, тогда как прокурорскому работнику, проводящему такую экспертизу, проще делать объективные выводы. По меткому замечанию С.М. Будатарова, «это подчас приводит к тому, что административные процедуры по оказанию публичных услуг «пишутся под себя», т.е. создают комфортные условия для служащих, которые обязаны такие услуги оказывать, а не для тех, кому они предоставляются» ${ }^{2}$;

Именно учитывая эти факторы антикоррупционная экспертиза, проводимая органами прокуратуры, представляется наиболее эффективной.

Существует мнение о том, что внутренняя экспертиза не может быть независимой. Речь в данном случае идет о признаке независимости экспертизы, как об объективном, беспристрастном проведении исследования, а не о виде экспертизы. Считается, что ведомственные отношения между начальником и подчиненным позволяют «регулировать» коррупциогенность нормы в зависимости от желания сторон. Свое мнение по этому поводу высказал А. В. Нестеров, отметив, что «в рамках данной гипотезы стали появляться мнения, что должна быть независимая экспертиза, в отличие от ведомственной экспертизы, якобы зависимой от ведомственных начальников» ${ }^{3}$.

А.В. Кудашкин придерживается точки зрения, что «независимость присуща антикоррупционной

2 Будатаров С.М. Объект и предмет антикоррупционной экспертизы правовых актов и их проектов // Вопросы судебной реформы: право, экономика, управление. 2009. № 3. С.36.

3 А. В. Нестеров. Правовые основания антикоррупционной экспертизы. экспертизе, проводимой органами прокуратуры, федеральным органом исполнительной власти в области юстиции (в том числе его территориальным подразделениям), но только в отношении нормативных правовых актов и их проектов, разрабатываемых иными органами (организациями), а также в инициативном порядке» ${ }^{4}$.

Не разделяет точки зрения А. В. Нестерова М. В. Гребенюк, считая, что «прокуратуру, орган юстиции и органы исполнительной власти весьма проблематично назвать «независимыми», поскольку все они представляют собой звенья государственной власти, в той или иной мере подпадающие под влияние должностных лиц, либо назначающих и смещающих их руководителей. Поэтому говорить о реальной объективности данных экспертиз не приходится, как не приходится говорить о независимости деталей или звеньев единого аппарата от управляющего данным аппаратом компьютера или контроллера. Кроме того, направление деятельности и прокуратуры и иных государственных органов строго ограничено рамками закона» 5 .

На основании вышеизложенного, становится очевидным, что «борьба с коррупцией и минимизация (ликвидация) последствий уже совершенных коррупционных правонарушений должны являться задачами в первую очередь следственных органов» ${ }^{6}$.

Несколько лет назад особой проблемой, стоявшей перед органами прокуратуры, было отсутствие законодательного регулирования возможности судебного оспаривания прокурором нормативных правовых актов по признаку их коррупциогенности. «На какие обстоятельства можно и должно ссылаться в заявлении, подаваемом прокурором, обосновывая необходимость изменения НПА, в котором выявлены коррупциогенные факторы и доказывая факт создания таким актом или проектом

\footnotetext{
4 Кудашкин А.В. Антикоррупционная экспертиза: теория и практика: научно-практическое пособие / А.В. Кудашкин. М. : Норма : ИНФРА-М, 2012. С. 49.

М.В. Гребенюк. Реализация законодательства о независимой антикоррупционной экспертизе и опыт работы Интернет-портала «Независимая антикоррупционная экспертиза» // Первая Всероссийская научно-практическая конференция «Реализация законодательства о независимой антикоррупционной экспертизе: проблемы и перспективы». Сборник материалов. - М. 2012. С. 49.

6 Гончаров, Д. Ю. Возможности антикоррупционной экспертизы в расследовании коррупционных преступлений / Д. Ю. Гончаров.// Вестник Московского университета МВД России. -2011. - № 6. - С. 223.
} 
НПА условий для проявления коррупции?»7. Прокуроры в таких спорных случаях были вынуждены искать в нормативном правовом акте противоречия законодательству, чтобы оспорить данный акт. Однако действующее законодательство не обладает процессуальным механизмом рассмотрения подобных заявлений и, как справедливо отмечается в литературе, «на практике далеко не всегда можно обосновать необходимость исключения коррупциогенных факторов через их прямое противоречие действующему законодательству, что осложняет механизм защиты прав конкретных субъектов и, как следствие, ослабляет возможность влияния на криминогенную ситуацию в России» ${ }^{8}$.

В 2010 году Генеральный прокурор Российской Федерации в своем распоряжении указал на необходимость решения данной проблемы 9 . Анализ судебной практики в настоящее время показал, что органы прокуратуры и суды стали использовать возможности действующей гражданско-процессуальной формы для признания незаконными нормативных предписаний, содержащих коррупциогенные факторы ${ }^{10}$.

\footnotetext{
Кудашкин, А. В., Дмитриев, Д. А. К вопросу о необходимости совершенствования правового регулирования проведения органами прокуратуры антикоррупционной экспертизы в целях повышения ее эффективности /А. В. Кудашкин, Д. А. Дмитриев. //Административное и муниципальное право. -2011 . - № 4. - С. 89.

8 Гулягин А.Ю. Проблемные вопросы и практика осуществления антикоррупционной экспертизы нормативных правовых актов и их проектов органами местного самоуправления // Государственная власть и местное самоуправление. - 2012. - №10.

9 Распоряжение Генерального прокурора Российской Федерации № 6/20p от 14.01.2010 “Об организации исполнения решения заседания президиума Совета при Президенте Российской Федерации по противодействию коррупции от 21 декабря 2009 года". Текст официально опубликован не был // СПС «Гарант».

10 Прокурор обратился в Верховный суд Республики Калмыкия с заявлением о признании недействующим пункта 1.3 Порядка заявления граждан о бесплатном предоставлении в собственность земельных участков, указывая на наличие в оспариваемой норме коррупциогенного фактора, выраженным в широте дискреционных полномочий. В обоснование своих требований прокурор сослался на то, что отсутствие в указанной норме конкретного срока формирования перечня предоставляемых земельных участков влечет за собой возможность произвольного установления таких сроков и соответственно сроков предоставления земельных участков. Исследовав материалы дела, суд пришел к выводу, что сроки выполнения работ невозможно регламентировать срок формирования перечня земельных участков, подлежащих бесплатной передаче в собственность граждан,
}

Таким образом, суды начинают рассматривать наличие в нормативном предписании коррупциогенных факторов как самостоятельное основание для признания такого предписания незаконным и недействующим, хотя часто органы прокуратуры стараются совместить признание наличия коррупциогенного фактора и несоответствие такого нормативного предписания вышестоящей по юридической силе норме права. Думается, что для полноценной реализации Закона об антикоррупционной экспертизе требуется внесение изменений в гражданско-процессуальное законодательство. В связи с этим, предлагаем в часть 1 статьи 251 Гражданского процессуального кодекса РФ «Подача заявления об оспаривании нормативных правовых актов» после слов: «а также прокурор» дополнить словами: «по делам об оспаривании нормативных правовых актов, содержащих коррупциогенные факторы».

В научной литературе была поставлена проблема осуществления антикоррупционной экс-

ввиду обязательности предварительного проведения работ по формированию каждого земельного участка в соответствии с требованиями градостроительного и земельного законодательства, сроки выполнения которых не зависят от усмотрения, как уполномоченного органа, так и Правительства РК. При изложенных обстоятельствах Верховный Суд Республики Калмыкия отказал в удовлетворении заявления прокурора. Решение было оспорено в Верховном Суде РФ, где Судебная коллегия по административным делам пришла к заключению, что вывод Верховного Суда РК сделан без учёта того, что реализация органами государственной власти субъекта РФ нормотворческих полномочий в области отношений, регулируемых земельным законодательством, предполагает соблюдение требований, предъявляемых федеральным законодателем к форме и содержанию правовой нормы, в том числе требования определённости, ясности, недвусмысленности правовой нормы. Методика проведения антикоррупционной экспертизы нормативных правовых актов и проектов нормативных правовых актов прямо относит нормы, устанавливающие для правоприменителя необоснованную широту дискреционных полномочий, в том числе отсутствие или неопределённость сроков, условий или оснований принятия решения, к коррупциогенному фактору. Поскольку неясность правового регулирования является самостоятельным основанием для признания оспариваемого акта или его части в такой редакции недействующими (пункт 25 постановления Пленума Верховного Суда Российской Федерации от 29 ноября 2007 г. № 48 «О практике рассмотрения судами дел об оспаривании нормативных правовых актов полностью или в части»), а также на основании изложенного Судебная коллегия по административным делам Верховного Суда РФ удовлетворила заявление прокурора.

Определение Судебной коллегии по административным делам Верховного Суда РФ от 04.04.2012 г. дело № 42-АПГ12-1 // Интернет-источник: Судебныерешения.рф. 
пертизы проектов нормативных правовых актов, разрабатываемых Следственным комитетом Российской Федерации, а именно: как и кем она должна проводиться ${ }^{11}$. СК России разрабатывает и представляет в установленном порядке Президенту РФ и в Правительство РФ проекты федеральных конституционных законов, федеральных законов, актов Президента РФ и Правительства РФ, а также подготавливает другие документы, по которым требуется решение Президента РФ или Правительства РФ, по вопросам, относящимся к установленной сфере деятельности (п.П. 3 п. 7 Положения о Следственном комитете Российской Федерации, утвержденном Указом Президента Российской Федерации от 14.01.2011 «Вопросы деятельности Следственного комитета Российской Федерации»). Однако, по мнению авторов, разрабатываемые СК России законопроекты не проходят внутреннюю антикоррупционную экспертизу органом-разработчиком, а проходят лишь экспертизу в Минюсте России. «Следовательно, ответственность за выявление коррупционных факторов в проектах нормативных правовых актов, разрабатываемых СК России, возлагается на Минюст России. По мнению авторов, необходимо рассмотреть вопрос о том, чтобы проекты нормативных правовых актов указанной категории проходили обязательную антикоррупционную экспертизу в СК России либо с привлечением специалистов следственных органов, которые как никто другие понимают существо и механизм процессов, протекающих в сфере уголовного судопроизводства на досудебной стадии» ${ }^{12}$.

Позволим себе не согласиться с представленной точкой зрения. На основании Приказа СК России от 03.07.12 № 38, Правовое управление Следственного комитета Российской Федерации осуществляет антикоррупционную экспертизу проектов нормативных правовых актов Следственного комитета Российской Федерации, а также нормативных правовых актов Следственного комитета в целях выявления в них коррупциогенных факторов и их последующего устранения ${ }^{13}$.

Таким образом, СК России принимает активное участие в исполнении антикоррупционной политики государства, а его акты проходят также внутреннюю экспертизу на коррупциогенность и только после этого попадают на проверку в Министерство юстиции РФ.

Надзорная экспертиза на настоящее время является одним из наиболее результативных видов экспертизы. В силу отсутствия зависимости от органов разработчиков нормативных правовых актов, с одной стороны, и регулярности проведения антикоррупционной экспертизы и, как следствие, наработанного большого опыта в этой области, с другой стороны, надзорная экспертиза сочетает в себе объективность общественной экспертизы и высокую квалификацию специалистов, присущую внутренней экспертизе. Перечисленные особенности делают надзорную экспертизу незаменимой.

\section{Библиография:}

1. ФЗ "Об антикоррупционной экспертизе нормативных правовых актов и проектов нормативных правовых актов" от 17 июля 2009 г. № 172-ФЗ. СЗ РФ. 2009. № 29 ст. 3609.

2. Будатаров С.М. Объект и предмет антикоррупционной экспертизы правовых актов и их проектов // Вопросы судебной реформы: право, экономика, управление. 2009. № 3. С.36.

3. Нестеров А.В. Правовые основания антикоррупционной экспертизы.

4. Кудашкин А.В. Антикоррупционная экспертиза: теория и практика: научно-практическое пособие / А.В. Кудашкин. - М. : Норма : ИНФРА-М, 2012. С. 49.

\footnotetext{
11 А.М. Багмет, Л.Е. Меркулова. К вопросу об антикоррупционной экспертизе нормативных правовых актов // Правовые проблемы противодействия коррупции: материалы Международной научной конференции Правовые проблемы противодействия коррупции». Москва, 2 ноября 2011 г. / отв. ред. Л.В. Андриченко, О.О. Журавлева. - М.: Институт законодательства и сравнительного правоведения при Правительстве Российской Федерации; ИД «Юриспруденция», 2012. - C.194.
}

\begin{abstract}
12 А.М. Багмет, Л.Е. Меркулова. К вопросу об антикоррупционной экспертизе нормативных правовых актов // Правовые проблемы противодействия коррупции: материалы Международной научной конференции Правовые проблемы противодействия коррупции». Москва, 2 ноября 2011 г. / отв. ред. Л.В. Андриченко, О.О. Журавлева. - М.: Институт законодательства и сравнительного правоведения при Правительстве Российской Федерации; ИД «Юриспруденция», 2012. - C.195.

13 П.1, 2 Приказа СК России от 03.07.2012 № 38 (ред. от 09.09.2013) “Об утверждении порядка проведения антикоррупционной экспертизы нормативных правовых актов (проектов нормативных правовых актов) Следственного комитета Российской Федерации" // РГ № 192, 22.08.2012.
\end{abstract}


5. Гребенюк М.В. Реализация законодательства о независимой антикоррупционной экспертизе и опыт работы Интернет-портала «Независимая антикоррупционная экспертиза» // Первая Всероссийская научно-практическая конференция «Реализация законодательства о независимой антикоррупционной экспертизе: проблемы и перспективы». Сборник материалов. - М. 2012. С. 49

6. Гончаров, Д. Ю. Возможности антикоррупционной экспертизы в расследовании коррупционных преступлений / Д. Ю. Гончаров. // Вестник Московского университета МВД России .-2011.-№ 6. - С. 223.

7. Кудашкин, А. В., Дмитриев, Д. А. К вопросу о необходимости совершенствования правового регулирования проведения органами прокуратуры антикоррупционной экспертизы в целях повышения ее эффективности / А. В. Кудашкин, Д. А. Дмитриев. //Административное и муниципальное право.-2011.-№ 4.-С. 89.

8. Гулягин А.Ю. Проблемные вопросы и практика осуществления антикоррупционной экспертизы нормативных правовых актов и их проектов органами местного самоуправления // Государственная власть и местное самоуправление. - 2012.-№10.

9. Распоряжение Генерального прокурора Российской Федерации № 6/20p от 14.01.2010 "Об организации исполнения решения заседания президиума Совета при Президенте Российской Федерации по противодействию коррупции от 21 декабря 2009 года". Текст официально опубликован не был // СПС «Гарант».

10. Багмет А. М.,Меркулова Л.Е. К вопросу об антикоррупционной экспертизе нормативных правовых актов // Правовые проблемы противодействия коррупции: материалы Международной научной конференции Правовые проблемы противодействия коррупции». Москва, 2 ноября 2011 г. / отв. ред. Л.В. Андриченко, О.О. Журавлева. М.: Институт законодательства и сравнительного правоведения при Правительстве Российской Федерации; ИД «Юриспруденция», 2012. - С.194.

11. Приказ СК России от 03.07.2012 № 38 (ред. от 09.09.2013) "Об утверждении порядка проведения антикоррупционной экспертизы нормативных правовых актов (проектов нормативных правовых актов) Следственного комитета Российской Федерации" // РГ № 192, 22.08.2012.

12. Дмитриев Д.А., Кудашкин А.В. Антикоррупционная экспертиза, проводимая органами прокуратуры. Вопросы совершенствования правового регулирования // NB: Административное право и практика администрирования. 2013. - 3. - C. 158 - 177. DOI: 10.7256/2306-9945.2013.3.710. URL: http://www.e-notabene.ru/al/article_710.html

13. Кабанов П.А. Некоторые формы взаимодействия институтов гражданского общества с органами местного самоуправления в области противодействия коррупции // Административное и муниципальное право. - 2012. 5. - С. 5 - 8 .

14. Кудашкин А.В., Дмитриев Д.А. К вопросу о необходимости совершенствования правового регулирования проведения органами прокуратуры антикоррупционной экспертизы в целях повышения ее эффективности // Административное и муниципальное право. - 2011. - 4. - С. 87 - 91.

15. Кабанов П.А. Рецензия на книгу: Будатаров С.М. Антикоррупционная экспертиза правовых актов и их проектов: понятие, порядок проведения: специализированный учебный курс / С.М. Будатаров; Саратовский Центр по исследованию проблем организованной преступности и коррупции. - Саратов: Изд-во ФГБоУ ВПО «Саратовская государственная юридическая академия», 2013. - 120 с. // Административное и муниципальное право. - 2013. 7. - С. 775 - 779. DOI: 10.7256/1999-2807.2013.7.9054.

16. Барциц И.Н. Правовые механизмы совершенствования экспертно-аналитического обеспечения противодействия коррупции // Журнал зарубежного законодательства и сравнительного правоведения. - 2012. - 4. - С. 27 34.

\section{References (transliterated):}

1. $\quad$ FZ "Ob antikorruptsionnoi ekspertize normativnykh pravovykh aktov i proektov normativnykh pravovykh aktov" ot 17 iyulya 2009 g. № 172 -FZ. SZ RF. 2009 . № 29 st. 3609.

2. Budatarov S.M. Ob"ekt i predmet antikorruptsionnoi ekspertizy pravovykh aktov i ikh proektov // Voprosy sudebnoi reformy: pravo, ekonomika, upravlenie. 2009. № 3. S.36.

3. Nesterov A.V. Pravovye osnovaniya antikorruptsionnoi ekspertizy.

4. Kudashkin A.V. Antikorruptsionnaya ekspertiza: teoriya i praktika: nauchno-prakticheskoe posobie / A.V. Kudashkin. - M.: Norma : INFRA-M, 2012. S. 49.

5. Grebenyuk M.V. Realizatsiya zakonodatel'stva o nezavisimoi antikorruptsionnoi ekspertize i opyt raboty Internet-portala «Nezavisimaya antikorruptsionnaya ekspertiza» // Pervaya Vserossiiskaya nauchno-prakticheskaya konferentsiya «Realizatsiya zakonodatel'stva o nezavisimoiantikorruptsionnoi ekspertize: problemy i perspektivy».Sbornikmaterialov.M. 2012. S. 49

6. Goncharov, D. Yu. Vozmozhnosti antikorruptsionnoi ekspertizy v rassledovanii korruptsionnykh prestuplenii / D. Yu. Goncharov. // Vestnik Moskovskogo universiteta MVD Rossii .-2011.-№ 6. - S. 223.

7. Kudashkin, A. V., Dmitriev, D. A. K voprosu o neobkhodimosti sovershenstvovaniya pravovogo regulirovaniya provedeniya organami prokuratury antikorruptsionnoi ekspertizy $\mathrm{v}$ tselyakh povysheniya ee effektivnosti /A. V. Kudashkin, D. A. Dmitriev. //Administrativnoe i munitsipal'noe pravo.-2011.-№ 4.-S. 89. 
Административное и муниципальное право 2 (86) 2015

8. Gulyagin A.Yu. Problemnye voprosy i praktika osushchestvleniya antikorruptsionnoi ekspertizy normativnykh pravovykh aktov i ikh proektov organami mestnogo samoupravleniya // Gosudarstvennaya vlast' i mestnoe samoupravlenie. 2012.-№10.

9. Rasporyazhenie General'nogo prokurora Rossiiskoi Federatsii № 6/20r ot 14.01.2010 "Ob organizatsii ispolneniya resheniya zasedaniya prezidiuma Soveta pri Prezidente Rossiiskoi Federatsii po protivodeistviyu korruptsii ot 21 dekabrya 2009 goda". Tekst ofitsial'no opublikovan ne byl // SPS «Garant».

10. Bagmet A. M.,Merkulova L.E. K voprosu ob antikorruptsionnoi ekspertize normativnykh pravovykh aktov // Pravovye problemy protivodeistviya korruptsii: materialy Mezhdunarodnoi nauchnoi konferentsii Pravovye problemy protivodeistviya korruptsii». Moskva, 2 noyabrya 2011 g. / otv. red. L.V. Andrichenko, O.O. Zhuravleva. - M.: Institut zakonodatel'stva i sravnitel'nogo pravovedeniya pri Pravitel'stve Rossiiskoi Federatsii; ID «Yurisprudentsiya», 2012. S.194.

11. Prikaz SK Rossii ot 03.07.2012 № 38 (red. ot 09.09.2013) "Ob utverzhdenii poryadka provedeniya antikorruptsionnoi ekspertizy normativnykh pravovykh aktov (proektov normativnykh pravovykh aktov) Sledstvennogo komiteta Rossiiskoi Federatsii" // RG № 192, 22.08.2012.

12. Dmitriev D.A., Kudashkin A.V. Antikorruptsionnaya ekspertiza, provodimaya organami prokuratury. Voprosy sovershenstvovaniya pravovogo regulirovaniya // NB: Administrativnoe pravo i praktika administrirovaniya. - 2013. 3. - C. 158 - 177. DOI: 10.7256/2306-9945.2013.3.710. URL: http://www.e-notabene.ru/al/article_710.html

13. Kabanov P.A. Nekotorye formy vzaimodeistviya institutov grazhdanskogo obshchestva $\mathrm{s}$ organami mestnogo samoupravleniya v oblasti protivodeistviya korruptsii // Administrativnoe i munitsipal'noe pravo. - 2012. - 5. - C. 5 - 8.

14. Kudashkin A.V., Dmitriev D.A. K voprosu o neobkhodimosti sovershenstvovaniya pravovogo regulirovaniya provedeniya organami prokuratury antikorruptsionnoi ekspertizy v tselyakh povysheniya ee effektivnosti // Administrativnoe i munitsipal'noe pravo. - 2011. - 4. - C. 87 - 91.

15. Kabanov P.A. Retsenziya na knigu: Budatarov S.M. Antikorruptsionnaya ekspertiza pravovykh aktov i ikh proektov: ponyatie, poryadok provedeniya: spetsializirovannyi uchebnyi kurs / S.M. Budatarov; Saratovskii Tsentr po issledovaniyu problem organizovannoi prestupnosti i korruptsii. - Saratov: Izd-vo FGBOU VPO «Saratovskaya gosudarstvennaya yuridicheskaya akademiya», 2013. - 120 s. // Administrativnoe i munitsipal'noe pravo. - 2013. - 7. - C. 775 - 779. DOI: $10.7256 / 1999-2807.2013 .7 .9054$.

16. Bartsits I.N. Pravovye mekhanizmy sovershenstvovaniya ekspertno-analiticheskogo obespecheniya protivodeistviya korruptsii // Zhurnal zarubezhnogo zakonodatel'stva i sravnitel'nogo pravovedeniya. - 2012. - 4. - C. 27 - 34. 